\title{
HUBUNGAN TINGKAT PENDIDIKAN DAN PENGETAHUAN DENGAN KEIKUTSERTAAN PENGGUNAAN KONTRASEPSI JANGKA PANJANG (MKJP) DI WILAYAH KERJA PUSKESMAS JEMBATAN KECIL
}

\author{
The Relationship between Level of Education and Knowledge with \\ Participation of Usage of Long-Term Contraception (MKJP) \\ in Working Area of Jembatan Kecil Public Health Center \\ Ruri Maiseptya Sari ${ }^{1}$, Leni Andriani ${ }^{1}$, Buyung Keraman ${ }^{2}$ \\ ${ }^{1}$ Program Studi DIV Kebidanan STIKES Tri Mandiri Sakti Bengkulu \\ ${ }^{2}$ Program Studi Matematika FMIPA Universitas Bengkulu \\ Email:Leniandriani@gmail.com
}

\begin{abstract}
ABSTRAK
Kontrasepsi MKJP merupakan kontrasepsi yang dianjurkan dalam program KB pemerintah karena terbukti lebih efisien dan efektif dengan biaya, tingkat kegagalan, efek samping dan komplikasi yang lebih rendah. Penelitian ini bertujuan untuk mempelajari hubungan tingkat pendidikan dan pengetahuan dengan keikutsertaan penggunaan kontrasepsi jangka panjang (MKJP) di wilayah kerja Puskesmas Jembatan Kecil. Jenis penelitian ini adalah Survey Analitik dengan desain Cross Sectional. Populasi yang diteliti dalam penelitian ini adalah seluruh akseptor KB aktif di wilayah kerja Puskesmas Jembatan Kecil pada bulan Juli-Agustus 2018. Pengambilan sampel dalam penelitian ini menggunakan teknik Accidental Sampling sebanyak 39 akseptor. Penelitian ini menggunakan data primer data sekunder. Analisis data dilakukan secara univariat dan bivariat dengan Uji Chi-Square $\left(\chi^{2}\right)$ dan Contingency Coefficient $(C)$. Hasil penelitian didapatkan dari 39 akseptor KB, terdapat 27 akseptor (69,2\%) tidak menggunakan alat kontrasepsi MKJP, 16 akseptor (41,0\%) berpendidikan dasar, 18 akseptor (46,2\%) berpengetahuan cukup. Ada hubungan yang signifikan antara tingkat pendidikan dengan keikutsertaan penggunaan kontrasepsi MKJP di wilayah kerja Puskesmas Jembatan Kecil dengan kategori hubungan sedang dan ada hubungan yang signifikan antara pengetahuan dengan keikutsertaan penggunaan MKJP di wilayah kerja Puskesmas Jembatan Kecil dengan kategori hubungan sedang. Diharapkan tenaga kesehatan dapat memberikan pendidikan kesehatan bagi akseptor KB tentang alat kontrasepsi yang sesuai dan efektif dalam menjarangkan kehamilan dengan melakukan penyuluhan, membagikan leaflet, poster, dan buku.
\end{abstract}

Kata Kunci: $\quad$ MKJP, pendidikan, pengetahuan

\section{ABSTRACT}

Long-term contraception (MKJP) is a contraception recommended in government family planning programs because it is proven to be more efficient and effective with lower costs, failure rates, side effects and complications. This study aims to study the relationship between education level and knowledge with the participation of MKJP usage in working area of Jembatan Kecil Public Health 
Center. The type of this research was Analytical Survey and the design was Cross Sectional. The population of this study was all active family planning acceptors in working area of Jembatan Kecil Public Health Center in July-August 2018. The Sampling technique in this study was Accidental Sampling. The sample total was 39 acceptors. This study used primary and secondary data. Data analysis was done by univariate and bivariate analyses with Chi-Square Test $\left(\chi^{2}\right)$ and Contingency Coefficient $(C)$. The results were obtained : of 39 family planning acceptors, 27 acceptors (69.2\%) did not use MKJP contraception, 16 acceptors (41.0\%) had basic education, and 18 acceptors (46.2\%) had sufficient knowledge. There was a significant relationship between the level of education with the MKJP usage in working area of Jembatan Kecil Public Health Center with the medium relationship category, there was a significant correlation between knowledge with the MKJP usage in working area of Jembatan Kecil Public Health Center with the medium relationship category. It was expected that health workers can provide health education for family planning acceptors about appropriate and effective contraceptives in spacing pregnancies by conducting counseling, distributing leaflets, posters and books.

Keywords: education, knowledge, MKJP

\section{A. Pendahuluan}

Strategi dari pelaksanaan program KB tercantum dalam Rencana Pembangunan Jangka Menengah (RPJM) tahun 2010-2014 tentang terkendalinya jumlah dan laju pertumbuhan penduduk. Salah satu arah kebijakan dari RPJM adalah meningkatkan penggunaan alat dan obat kontrasepsi jangka panjang (MKJP). Semakin banyak penduduk yang mengikuti program $\mathrm{KB}$, maka angka kenaikan laju pertumbuhan penduduk yang terus meningkat setiap tahunnya akan bisa ditekan (BKKBN, 2015).

Pilihan jenis alat kontrasepsi di Indonesia umumnya masih terarah pada kontrasepsi Non-MKJP seperti suntik dan pil. Sementara kebijakan program KB pemerintah lebih mengarah pada penggunaan kontrasepsi MKJP seperti IUD, MOP, dan MOW. Anjuran yang disampaikan program didasarkan pada pertimbangan ekonomi penggunaan alat kontrasepsi nonhormonal yang dinilai lebih efisien. Efisiensi yang dimaksud berkaitan dengan ketersediaan anggaran penyediaan kontrasepsi dengan efektivitas, biaya, tingkat kegagalan, efek samping, dan komplikasi. Sementara dari sisi medis, alat kontrasepsi nonhormonal dinilai lebih aman bagi kesehatan tubuh. Sebaliknya, alat kontrasepsi hormonal selain tidak ekonomis juga sangat berpengaruh terhadap kesehatan dalam jangka waktu panjang (BKKBN, 2015) Rendahnya pemakaian kontrasepsi MKJP dikarenakan ketidaktahuan akseptor tentang kelebihan metode tersebut. Ketidaktahuan akseptor tentang kelebihan metode kontrasepsi jangka panjang (MKJP) disebabkan informasi yang disampaikan petugas KB kurang lengkap. Masih banyak pemakaian kontrasepsi yang tidak rasional/tidak dianjurkan oleh pemerintah, sehingga promosi, KIE tentang kontrasepsi rasional, efektif dan efisien untuk terus ditingkatkan (BKKBN, 2015)

Profil Kesehatan Provinsi Bengkulu tahun 2015, jumlah peserta KB aktif di Provinsi Bengkulu dengan 
Metode Kontrasepsi Jangka Panjang (MKJP) sebanyak $47.779 \quad(18,5 \%)$ akseptor dan KB Aktif dengan NonMKJP sebanyak $210.754 \quad(81,5 \%)$ akseptor (Dinkes Provinsi Bengkulu, 2016)

Berdasarkan data Dinas Kesehatan Kota Bengkulu pada tahun 2017 didapatakan jumlah peserta KB aktif di Kota Bengkulu sebanyak 46.914 akseptor dengan jumlah peserta KB aktif dengan MKJP sebanyak $12.808(27,3 \%)$ akseptor dan KB Aktif dengan Non-MKJP sebanyak 34.106 $(72,7 \%)$ akseptor. Dengan puskesmas tertinggi pengguna MKJP pada Puskesmas Basuki Rahmat sebanyak 1.445 akseptor diikuti oleh Puskesmas Sidomulyo sebanyak 1.443 akseptor dan Puskesmas Sukamerindu sebanyak 1.317 akseptor. Dan puskesmas terendah pengguna MKJP terdapat pada Puskesmas Kuala Lempuing sebanyak 87 akseptor. Sedangkan Puskesmas Jembatan Kecil dengan dengan jumlah akaseptor KB MKJP sebanyak 608 akseptor (Dinkes Kota Bengkulu, 2017).

Berdasarkan data Puskesmas Jembatan Kecil didapatkan pada tahun 2015 jumlah akseptor KB aktif sebanyak 3.425 akseptor dengan jumlah peserta MKJP sebanyak 1.116 $(32,6 \%)$ akseptor, pada tahun 2016 jumlah akseptor KB aktif sebanyak 2.364 akseptor dengan jumlah peserta MKJP sebanyak 963 akseptor $(30,1 \%)$ akseptor dan pada tahun 2017 jumlah akseptor KB aktif sebanyak 2.987 akseptor dengan jumlah peserta MKJP sebanyak $608(20,4 \%)$ akseptor

Bedasarkan survey awal peneliti pada tanggal 7 Juni 2018 di Puskesmas Jembatan Kecil terdapat 7 akseptor peserta KB aktif yang sedang berkunjung ke Puskesmas Jembatan Kecil. Dari 6 peserta KB aktf terdapat 2 akseptor menggukan MKJP dan 5 akseptor menggunakan Non-MKJP. Dari 2 akseptor menggunakan MKJP terdapat 1akseptor dengan pendidikan tinggi dan 1 akseptor dengan pendidikan menengah. Selain itu juga kedua-duanya memahami tentang pengertian,manfaat, kelebihan dan kekurangan MKJP yang yang digunakan. Dari 5 akseptor pengguna KB Non-MKJP terdapat 1 akseptor dengan pendidikan tinggi, 2 akseptor dengan pendidikan menengah dan 2 akseptor dengan pendidikan dasar, dari 5 akseptor pengguna Non-MKJP terdapat 1 akseptor yang mengatahui tentang tentang pengertian, manfaat, kelebihan dan kekurangan MKJP dan 4 akseptor tidak mengetahui tentang pengertian, manfaat, kelebihan dan kekurangan MKJP

Rumusan masalah dalam penelitian ini adalah adakah hubungan tingkat pendidikan dan pengetahuan dengan keikutsertaan penggunaan MKJP di wilayah kerja Puskesmas Jembatan Kecil?. Tujuan penelitian ini adalah untuk mempelajari hubungan tingkat pendidikan dan pengetahuan dengan keikutsertaan penggunaan MKJP di wilayah kerja Puskesmas Jembatan Kecil.

\section{B. Metode Penelitian}

Jenis Penelitian ini ini adalah Survey Analitik dengan desain Cross Sectional. Populasi yang diteliti dalam penelitian ini adalah seluruh akseptor KB aktif di wilayah kerja Puskesmas Jembatan Kecil pada bulan JuliAgustus 2018. Pengambilan sampel dalam penelitian ini menggunakan teknik Accidental Sampling sebanyak 39 akseptor. Penelitian ini menggunakan data primer data sekunder. Analisis data dilakukan secara univariat, bivariat dengan $U j i$ Chi-Square $\left(\chi^{2}\right)$ dan Contingency Coefficient $(C)$. 


\section{Hasil Penelitian}

1. Analisis Univariat

Analisis univariat dilakukan untuk memperoleh gambaran tentang variabel independent (pendidikan dan pengetahuan) dan variabel dependent (penggunaan MKJP) di wilayah kerja Puskesmas Jembatan Kecil. Setelah penelitian dilaksanankan maka diperoleh data sebagai berikut :

Tabel 1.

Gambaran Penggunaan Kontrasepsi Jangka Panjang (MKJP) di Wilayah Kerja Puskesmas Jembatan Kecil

\begin{tabular}{ccc}
\hline Penggunaan MKJP & Frekuensi & Persentase (\%) \\
\hline Tidak & 27 & 69,2 \\
Ya & 12 & 30,8 \\
\hline Total & 39 & 100,0 \\
\hline
\end{tabular}

Berdasarkan Tabel 1, tampak bahwa dari 39 akseptor KB di wilayah kerja Puskesmas Jembatan Kecil terdapat 27 akseptor $(69,2 \%)$ tidak menggunakan alat kontrasepsi MKJP dan 12 akseptor $(30,8 \%)$ menggunakan alat kontrasepsi MKJP.

Tabel 2.

Gambaran Tingkat Pendidikan Akseptor KB di Wilayah Kerja Puskesmas Jembatan Kecil

\begin{tabular}{ccc}
\hline Pendidikan & Frekuensi & Persentase (\%) \\
\hline Dasar & 16 & 41,0 \\
Menengah & 13 & 33,3 \\
Tinggi & 10 & 25,6 \\
\hline Total & 39 & 100,0 \\
\hline
\end{tabular}

Berdasarkan Tabel 2, tampak bahwa dari 39 akseptor KB di wilayah kerja Puskesmas Jembatan Kecil terdapat 16 akseptor $(41,0 \%)$ dengan pendidikan dasar, 13 akseptor $(33,3 \%)$ dengan pendidikan menengah dan 10 akseptor $(25,6 \%)$ dengan pendidikan tinggi.

Tabel 3.

Gambaran Pengetahuan Akseptor KB di Wilayah Kerja Puskesmas Jembatan Kecil

\begin{tabular}{ccc}
\hline Pengetahuan & Frekuensi & Persentase (\%) \\
\hline Kurang & 12 & 30,8 \\
Cukup & 18 & 46,2 \\
Baik & 9 & 23,1 \\
\hline Total & 39 & 100,0 \\
\hline
\end{tabular}

Berdasarkan Tabel 3, tampak bahwa dari 39 akseptor KB terdapat 12 akseptor $(30,8 \%)$ berpengetahuan kurang, 18 akseptor (46,2\%) berpengetahuan cukup dan 9 akseptor $(23,1 \%)$ berpengetahuan baik. 


\section{Analisis Bivariat}

Analisis bivariat digunakan untuk melihat hubungan antara variabel independent (penddikan dan pengetahuan) dan variabel dependent (penggunaan MKJP).

Tabel 4.

Hubungan Tingkat Pendidikan dengan Keikutsertaan Penggunaan Kontrasepsi Jangka Panjang (MKJP) di Wilayah Kerja Puskesmas Jembatan Kecil

\begin{tabular}{|c|c|c|c|c|c|c|c|c|c|}
\hline \multirow{3}{*}{ Pendidikan } & \multicolumn{4}{|c|}{ Penggunaan MKJP } & \multirow{2}{*}{\multicolumn{2}{|c|}{ Total }} & \multirow{3}{*}{$\chi^{2}$} & \multirow{3}{*}{$p$} & \multirow{3}{*}{$\mathrm{C}$} \\
\hline & \multicolumn{2}{|c|}{ Tidak } & \multicolumn{2}{|c|}{$\mathrm{Ya}$} & & & & & \\
\hline & $\mathrm{F}$ & $\%$ & $\mathrm{~F}$ & $\%$ & $\mathrm{~F}$ & $\%$ & & & \\
\hline Dasar & 14 & 87,5 & 2 & 12,5 & 16 & 100 & \multirow{4}{*}{6,518} & \multirow{4}{*}{0,038} & \multirow{4}{*}{0,378} \\
\hline Menengah & 9 & 69,2 & 4 & 30,8 & 13 & 100 & & & \\
\hline Tinggi & 4 & 40,0 & 6 & 60,0 & 10 & 100 & & & \\
\hline Total & 27 & 69,2 & 12 & 30,8 & 39 & 100 & & & \\
\hline
\end{tabular}

Berdasarkan Tabel 5, didapatkan bahwa dari 16 akseptor dengan pendidikan dasar terdapat 14 akseptor tidak menggunakan alat kontrasepsi MKJP dan 2 akseptor menggunakan alat kontrasepsi MKJP. Dari 13 akseptor dengan pendidikan menengah terdapat 9 akseptor tidak menggunakan alat kontrasepsi MKJP dan 4 akseptor menggunakan alat kontrasepsi MKJP. Dari 10 akseptor dengan pendidikan tinggi terdapat 4 akseptor tidak menggunakan alat kontrasepsi MKJP dan 6 akseptor menggunakan alat kontrasepsi MKJP

Hasil uji statistic Pearson ChiSquare didapat nilai $\chi^{2}=6,518$ dengan $\mathrm{p}=0,038<\alpha(0,05)$ berarti signifikan, maka Ho ditolak Ha diterima. Hasil uji Contingency Coefficient didapat nilai $\mathrm{C}=0,378$ dengan $\mathrm{p}=0,038<\alpha 0,05$ berarti signifikan.

Tabel 5.

Hubungan Pengetahuan dengan Keikutsertaan Penggunaan Kontrasepsi Jangka Panjang (MKJP) di Wilayah Kerja Puskesmas Jembatan Kecil

\begin{tabular}{|c|c|c|c|c|c|c|c|c|c|}
\hline \multirow{3}{*}{ Pengetahuan } & \multicolumn{4}{|c|}{ Penggunaan MKJP } & \multirow{2}{*}{\multicolumn{2}{|c|}{ Total }} & \multirow{3}{*}{$\chi^{2}$} & \multirow{3}{*}{$p$} & \multirow{3}{*}{$\mathrm{C}$} \\
\hline & \multicolumn{2}{|c|}{ Tidak } & \multicolumn{2}{|c|}{$\mathrm{Ya}$} & & & & & \\
\hline & $\mathrm{F}$ & $\%$ & $\mathrm{~F}$ & $\%$ & $\mathrm{~F}$ & $\%$ & & & \\
\hline Kurang & 11 & 91,7 & 1 & 8,3 & 12 & 100 & \multirow{4}{*}{8,356} & \multirow{4}{*}{0,015} & \multirow{4}{*}{0,420} \\
\hline Cukup & 13 & 72,2 & 5 & 27,8 & 18 & 100 & & & \\
\hline Baik & 3 & 33,3 & 6 & 66,7 & 9 & 100 & & & \\
\hline Total & 27 & 69,2 & 12 & 30,8 & 39 & 100 & & & \\
\hline
\end{tabular}

Berdasarkan Tabel 5, didapatkan dari 12 akseptor dengan pengetahuan kurang terdapat 11 akseptor tidak menggunakan alat kontrasepsi MKJP dan 1 akseptor menggunakan alat kontrasepsi MKJP. Dari 18 akseptor dengan pengetahuan cukup terdapat 13 akseptor tidak menggunakan alat kontrasepsi MKJP dan 5 akseptor menggunakan alat kontrasepsi MKJP. Dari 9 akseptor dengan pengetahuan baik terdapat 3 akseptor tidak menggunakan alat kontrasepsi MKJP 
dan 6 akseptor menggunakan alat kontrasepsi MKJP

Hasil uji statistic Pearson ChiSquare didapat nilai $\chi^{2}=8,356$ dengan $\mathrm{p}=0,015<\alpha(0,05)$ berarti signifikan, maka Ho ditolak Ha diterima. Hasil uji Contingency Coefficient didapat nilai $\mathrm{C}=0,420$ dengan $\mathrm{p}=0,010<\alpha(0,05)$ berarti signifikan.

\section{Pembahasan}

Berdasarkan hasil penelitian, tampak bahwa dari 39 akseptor KB di wilayah kerja Puskesmas Jembatan Kecil terdapat 27 akseptor $(69,2 \%)$ tidak menggunakan alat kontrasepsi MKJP dan 12 akseptor (30,8\%) menggunakan alat kontrasepsi MKJP. Kondisi ini menunjukkan bahwa masih tingginya angka penggunaan alat kontrasepsi non-MKJP hal ni dikarenakan pada pada akseptor $\mathrm{KB}$ yang tidak menggunakan $\mathrm{KB}$ dengan metode MKJP mengatakan tidak berani menggunakan karena tertanam di dalam tubuh. Selain itu juga terdapat kaseptor yang menggunakan alat kontrasepsi MKJP dengan alasan tidak terlalu repot untuk cara penggunaannya dan tidak akan lupa, karna jangka waktunya yang lama.

Berdasarkan hasil penelitian, tampak bahwa dari 39 akseptor KB di wilayah kerja Puskesmas Jembatan Kecil terdapat 16 akseptor $(41,0 \%)$ dengan pendidikan dasar, 13 akseptor $(33,3 \%)$ dengan pendidikan menengah dan 10 akseptor (25,6\%) dengan pendidikan tinggi. Kondisi tersebut menunjukkan bahwa hampir sebagian yaitu $41 \%$ akseptor KB di wilayah kerja Puskesmas Jembatan Kecil memiliki pendidikan yang rendah yaitu pendidikan dasar. Pendidikan dasar meliputi pendidikan di jenjang SD dan SMP. Pendidikan dasar yang yang dimiliki responden dipengaruhi oleh social ekonomi yang dimiliki oleh responden, selain status social ekonomi yang rendah kondisi social budaya juga mempengaruhi pendidikan responden dan semakin banyak yang memiliki pendidikan yang tinggi maka semakin besar pengaruh social budaya dilingkungannya

Berdasarkan hasil penelitian, tampak bahwa dari 39 akseptor KB di wilayah kerja Puskesmas Jembatan Kecil terdapat 12 akseptor (30,8\%) dengan pengetahuan kurang, 18 akseptor $(46,2 \%)$ dengan pengetahuan cukup dan 9 akseptor $(23,1 \%)$ dengan pengetahuan baik.

Masih banyaknya ibu yang memiliki pengetahuan kurang karena rata-rata ibu banyak yang hanya lulusan SMP, SMA, SD, bahkan ada juga yang tidak sekolah, dan hanya beberapa akseptor yang sudah sarjana. Selain itu banyak juga ibu yang malas mengikuti penyuluhan kesehatan yang diberikan tim puskesmas, sehingga informasi tentang jenis dan manfaat kontrasepsi tidak pernah tersalurkan kepada masyarakat. Kondisi inilah yang membuat banyak ibu yang tidak/kurang mengerti tentang jenisjenis kontrasepsi serta keuntungan dan kerugian yang bisa ditimbulkannya.

Berdasarkan hasil penelitian didapatkan dari 16 akseptor dengan pendidikan dasar terdapat 14 akseptor tidak menggunakan alat kontrasepsi MKJP. Kondisi ini menunjukkan bahwa masih terdapat ibu dengan pendidikan yang rendah yaitu pendidikan dasar, sehingga hal ini menyebabkan kurangnya pengetahuan ibu tentang alat kontrasepsi AKDR. Dengan pendidikan yang rendah maka akan menyulitkan seseakseptor dalam menerima informasi baru sehngga mempengaruhi pemlihan alat kontrasepsi yang digunakan dan lebih memilih alat kontrasepsi yang kebanyakan akseptor gunakan, bukan 
berdasarkan kecocokan atau kebutuhan.

Dari akseptor dengan pendidikan dasar terdapat 2 akseptor menggunakan alat kontrasepsi MKJP. Kondisi ini menunjukkan walaupun responden dengan pendidikan dasar tetapi memilih alat kontrasepsi MKJP, hal ini dapat terjadi walaupun ibu dengan pendidikan dasar, namun dengan akses dan ketersediaan informasi yang mudah didapat sehingga ibu memiliki pengetahuan yang baik mengenai alat kontrasepsi MKJP sehingga akseptor lebih memilih menggunakan MKJP. Selain itu fakor pekerjaan dan umur juga mempengaruhi ibu dalam penggunaan kontrasepsi yaitu seperti pada Ny. T dengan usia $>35$ tahun lebih memilih kontrasepsi AKDR karena pada umur $>35$ tahun adalah masa penghentian kehamilan sehingga ibu memilih alat kontrasepsi dengan efektvitas yang tinggi dan masa penggunaan yang relatif lama. Selain itu faktor pekerjaan juga mempengaruhi pemilihan alat kontrasepsi seperti pada Ny. W yang bekerja dan memiliki sedikit waktu luang untuk melakukan kontrol rutin $\mathrm{KB}$, sehingga ibu memilih alat kontrasepsi dengan jangka waktu yang lama dan tidak perlu melakukan kontrol rutin setiap bulan seperti KB pil dan suntik, maka ibu lebih memilih alat kontrasepsi implant.

Dari 13 akseptor dengan pendidikan menengah terdapat 9 akseptor tidak menggunakan alat kontrasepsi MKJP dan 4 akseptor menggunakan alat kontrasepsi MKJP. Kondisi ini menunjukkan bahwa dengan pendidikan menengah saja belum cukup untuk menjamin ibu lebih memilih menggunakan kontrasepsi MKJP, maka harus didukung dengan peran bidan dalam membantu akseptor dalam memilih alat kontrasepsi yang sesuai dengan kebutuhannya seperti dengan memberikan pendidikan kesehatan saat akseptor sedang berkunjung ke pukesmas

Dari 10 akseptor dengan pendidikan tinggi terdapat 4 akseptor tidak menggunakan alat kontrasepsi MKJP. Hal ini menunjukkan bahwa akseptor memiliki cocokan menggunakan alat kontrasepsi lain dan tidak memiliki dampak komplikasi yang diakibatkannya sehingga tidak memilih menggunkan alat kontrasepsi MKJP dan lebih memilih menggunakan alat kontrasepsi yang lainya. Selain kondisi tersebut akseptor juga masih dalam penggunaan alat kontrasepsi hormonal dengan usia yang masih cukup muda sehingga lebih memilih menggunakan alat kontrasepsi yang lainnya seperti suntik dan pil.

Dari akseptor dengan pendidikan tinggi terdapat 6 akseptor menggunakan alat kontrasepsi MKJP. Kondisi ini menunjukkan bahwa dengan pendidikan yang baik maka akan mempengaruhi pengetahuan ibu dan dengan pengetahuan yang baik akan mempermudah ibu untuk mendapatkan informassi tentang MKJP sehingga ibu lebih memilih alat kontrasepsi MKJP

Didapat hubungan yang signifikan antara tingkat pendidikan dengan keikutsertaan penggunaan kontrasepsi jangka panjang (MKJP) di wilayah kerja Puskesmas Jembatan Kecil. Hasil ini sejalan dengan teori menurut Liando (2013), yang menyebutkan bahwa semakin tinggi tingkat pendidikan ibu akan menambah pengetahuan ibu dalam pemilihan alat kontrasepsi yang cocok untuk dirinya. Ini disebabkan seseakseptor yang berpendidikan tinggi akan lebih luas pandangannya dan lebih mudah menerima ide dan tata cara kehidupan yang baru, termasuk pentingnya 
keikutsertaan dalam pemilihan alat kontrasepsi. Namun seakseptor dengan pendidikan rendah pun dapat mengambil keputusan dengan benar karena pengetahuan yang dia dapatkan dari majalah, buku, televisi atau lainnya

Didapat katagori hubungan sedang antara tingkat pendidikan dengan keikutsertaan penggunaan kontrasepsi jangka panjang (MKJP) di wilayah kerja Puskesmas Jembatan Kecil. Hasil ini menunjukkan bahwa terdapat faktor lain yang mempengaruhi penggunaan MKJP selain pendidikan seperti, umur, paritas, pengetahuan dan dukungan suami.

Hasil penelitian ini sejalan dengan penelitian Rotie (2015) yang melakukan penelitian tentang hubungan pengetahuan dan tingkat pendidikan ibu dengan penggunaan metode kontrasepsi efektif terpilih, didapatkan hasil bahwa terdapat hubungan yang sgnifkan antara tingkat pendidikan dengan dengan penggunaan metode kontrasepsi efektif terpilih di Puskesmas Lolak Kabupaten Bolaang Mongondow

Berdasarkan hasil penelitian didapatkan dari 12 akseptor dengan pengetahuan kurang terdapat 11 akseptor tidak menggunakan alat kontrasepsi MKJP. Kondisi ini menunjukkan bahwa dengan pengetahaun yang kurang akan mempengaruhi perilakuu kesehatan seseakseptor termasuk dalam memlih alat kontrasepsi yang sesuai. Hasil ini sejalan dengan teori menurut Hartanto (2014) pengetahuan yang kurang akan mempengaruhi sikap dan perilaku seseakseptor dalam kehidupannya, bila seseakseptor memiliki pengetahuan tentang suatu hal maka akan timbul pemikiran tentang segi positif dan negatif mengenai hal tersebut, pengetahuan ini berpengaruh terhadap sikap dan perilaku seseakseptor sesuai dengan pemukirannya, kalau positif akan menimbulkan sikap positif, demikian juga sebaliknya jika negatif akan menimbulkan sikap negatif pula, misalnya pengetahuan ibu kurang tentang alat kontrasepsi maka ibu tersebut tidak akan memiliki keinginan untuk menggunakan alat kontrasepsi yang cocok untuk dirinya.

Dari 12 akseptor dengan pengetahuan kurang terdapat 1 akseptor menggunakan alat kontrasepsi MKJP. Adanya ibu yang menggunakan KB dengan metode MKJP walaupun berpengetahuan rendah, seperti pada Ny. I yang mengikuti saran bidan yang didatanginya karena ibu yang sudah memiliki anak dengan jarak yang cukup dekat serta ibu berusia > 35 tahun yang sudah tidak dianjurkan untuk hamil kembali, sehingga disarankan menggunakan $\mathrm{KB}$ dengan metode MKJP

Dari 18 akseptor dengan pengetahuan cukup terdapat 13 akseptor tidak menggunakan alat kontrasepsi MKJP dan 5 akseptor menggunakan alat kontrasepsi MKJP. Pengetahun yang cukup dimliki responden dapat mendukung dalam memilih alat kontrasepsi yang sesuai seperti kontrasepsi MKJP. Namun pengetahuan yang cukup saja tidak cukup untuk membantu ibu dalam memilih alat kontrasepsi MKJP, dibuktikan masih ada ibu yang menggunakan alat kontrasepsi nonMKJP padahal ibu dengan pengetahuan yang cukup, hal ini disebabkan kurangnya dukungan suami saat ibu memutuskan dalam menggunakan kontrasepsi MKJP. Dukungan suami dapat berupa penguatan dan dukungan mental, karena pada umumnya ibu ibu merasa takut untuk memilih alat kontrasepsi 
MKJP karena tertanam didalam tubuh dan cara pemasangannya pun dibutuhkan tindakan khusus dan tdak sesimpel alat kontrasepsi non-MKJP.

Dari 9 akseptor dengan pengetahuan baik terdapat 3 akseptor tidak menggunakan alat kontrasepsi MKJP. Kondisi ini karena walaupun ibu berpengetahuan tinggi, tetapi tidak ada dukungan suami serta rasa takut pada tindakan KB dengan metode MKJP membuat ibu memutuskan untuk ber $\mathrm{KB}$ dengan metode lain seperti suntik dan pil seperti pada $\mathrm{Ny}$. $\mathrm{R}$ dan Ny. A. Selain itu faktor umur juga mempengaruhi seperti pada $\mathrm{Ny}$. $\mathrm{H}$ yang telah berumur 25 tahun dan memilih menggunakan alat kontrasepsi suntik karena mash memiliki rencana hamil dalam waktu yang dekat.

Dari akseptor KB dengan pengetahuan baik terdapat dan 6 akseptor menggunakan alat kontrasepsi MKJP. Dengan pengetahuan yang baik maka akan mempengaruhi perilaku kesehatan seseakseptor sehingga akan mempermudah dalam pemilihan alat kontrasepsi MKJP.

Didapatkan hubungan yang signifikan antara pengetahuan dengan keikutsertaan penggunaan kontrasepsi jangka panjang (MKJP) di wilayah kerja Puskesmas Jembatan Kecil. Kondisi ini menunjukkan bahwa pengetahuan mempunyai pengaruh terhadapa perilaku pemilihan alat kontrasepsi. Dengan pengetahuan yang baik akan memudahkan akseptor KB dalam memilih alat kontrasepsi yang sesuai baginya dan sebaliknya dengan pengetahuan yang kurang akan menyebabkan akseptor sulit untuk memilih alat kontrsepsi yang sesuai, dan lebih memilih alat kontrasepsi yang kebanyakan akseptor gunakan dan hanya ikut-kutan saja dalam memilih alat kontrasepsi
Didapat katagori hubungan sedang antara pengetahuan dengan keikutsertaan penggunaan kontrasepsi jangka panjang (MKJP) di wilayah kerja Puskesmas Jembatan Kecil. Hal ini menunjukkan bahwa masih terdapat faktor lain yang berhubungan dengan pemilihan kontrasepsi MKJP seperti umur, paritas dan dukungan suami. Didukung oleh manuaba (2010) menyebutkan bahwa stimulus yang diterima oleh subjek langsung menerima tindakan, artinya seseakseptor dapat bertindak dan berperilaku baru tanpa mengetahui terlebih dahulu makna stimulus yang diterimanya. Dengan kata lain tindakan seseakseptor tidak harus didasari pengetahuan. Bisa dari pengalaman tapi penentuan perilaku tidak didasari oleh pengalaman. Maka dari itu Pengetahuan besar pengaruhnya pada pemilihan alat kontrasepsi.

Sejalan dengan penelitan Rosmadewi (2015), yang melakukan penelitian tentang hubungan pengetahuan dan tingkat ekonomi dengan penggunaan alat kontrasepsi di wilayah Puskesmas Sekampung Kabupaten Lampung Timur, didapatkan hasil bahwa terdapat hubungan yang signifikan antara pengetahuan dengan penggunaan alat kontrasepsi di wilayah Puskesmas Sekampung Kabupaten Lampung Timur.

\section{E. Kesimpulan}

1. Dari 39 akseptor $\mathrm{KB}$ terdapat 27 akseptor $\quad(69,2 \%) \quad$ tidak menggunakan alat kontrasepsi MKJP.

2. Dari 39 akseptor $\mathrm{KB}$ terdapat 16 akseptor $\quad(41,0 \%) \quad$ dengan pendidikan dasar.

3. Dari 39 akseptor KB terdapat 18 akseptor $\quad(46,2 \%)$ dengan pengetahuan cukup. 
4. Ada hubungan yang signifikan antara tingkat pendidikan dengan keikutsertaan penggunaan kontrasepsi jangka panjang (MKJP) di wilayah kerja Puskesmas Jembatan Kecil, dengan kategori hubungan sedang.

5. Ada hubungan yang signifikan antara pengetahuan dengan keikutsertaan penggunaan kontrasepsi jangka panjang (MKJP) di wilayah kerja Puskesmas Jembatan Kecil, dengan kategori hubungan sedang.

\section{Daftar Pustaka}

BKKBN. (2015). Hasil Pelaksanaan Sub Sistem Pencatatan dan Pelaporan Pelayanan Kontrasepsi. Direktorat Pelaporan dan Statistik. Jakarta

BKKBN. (2015). Pedoman Penyelenggaraan Pendidikan dan Pelatihan Fungsional Dasar Bidang Pengendalian Penduduk, Keluarga Berencana, dan Pembangunan Keluarga bagi Penyuluh Keluarga Berencana. Jakarta: Pusat Pendidikan Kependudukan dan Keluarga Berencana

Depdiknas. (2003). Undang-undang RI No. 20 tahun 2003 tentang Sistem Pendidikan Nasional. Jakarta: Depdiknas.
Dinkes Kota Bengkulu. (2017). Profil Kesehatan Kota Bengkulu. Kota Bengkulu

Dinkes Prov. Bengkulu. (2015). Profil Kesehatan provinsi Bengkulu.Bengkulu

Hartanto. (2014). Keluarga Berencana dan Kontrasepsi. Jakarta: Sinar Harapan.

Liando, H. (2013). Panduan praktis pelayanan kontrasepsi. Jakarta: Pustaka Sinar Harapan

Manuaba, I.B.G. (2010). Ilmu Kebidanan, Penyakit Kandungan Dan KB Jakarta: EGC

Rosmadewi. (2015). Hubungan Pengetahuan dan Tingkat Ekonomi dengan Penggunaan Alat Kontrasepsi di wilayah Puskesmas Sekampung Kabupaten Lampung Timur. Jurnal Kesehatan Metro Sai Wawai, VIII (1) : 19-24. Diunduh dari : http://poltekkestjk.ac.id/ejurnal/index.php/JKM/ article/view/165

Rotie. (2015). Hubungan Pengetahuan Dan Tingkat Pendidikan Ibu Dengan Penggunaan Metode Kontrasepsi Efektif Terpilih. Diakses pada tanggal 14 Maret 2018, dari https://ejurnal.com/2016/12/hubunganpengetahuan-dan-tingkat.html 